\title{
Multivariate Statistical Analysis of Industrial Overcapacity in Chinese Provinces
}

\author{
Wu Pan ${ }^{1, a}$ \\ ${ }^{1}$ South China University of Technology, Economic and trade institute. \\ Panyu ,Guangzhou ,Guangdong , China \\ awp_6767@163.com
}

Keywords: Industry, Overcapacity, Multivariate statistical.

\begin{abstract}
In recent years, excess production capacity has been plagued by China's economic development, especially under the background of the new normal, excess capacity in the short term and long term will cause certain negative influence to our country economy, destroy the healthy development of the industrial structure, increase the risk of a total economic fluctuations, hinder economic growth mode transformation, reduce the quality of efficiency of economic growth. Overcapacity problem has aroused high attention, and relevant government departments have to adopt a series of measures to adjust the problem, but so far has not been effectively resolved. In this context, study the formation mechanism of excess production capacity, should have very important guiding significance. In this paper, based on multivariate statistical method, the utilization of capacity of 31 provinces in China for principal component analysis, it is concluded that the capacity utilization first reflected in terms of input and output, the second is the use of funds, and there is obvious regional difference in the capacity utilization, better utilization of capacity, economically developed provinces and eastern overall capacity utilization of the Midwest.
\end{abstract}

\section{我国各省份工业产能过剩的多元统计分析 \\ 吴盼 ${ }^{1, a}$ \\ ${ }^{1}$ 华南理工大学经济与贸易学院, 番禺, 广州, 广东, 中国 \\ awp_6767@163.com}

关键词：工业、产能过剩、多元统计

摘要.近年来, 产能过剩一直困扰着中国经济的发展, 尤其在新常态背景下，过剩的产能在短 期和长期都会对我国经济造成一定的负面影响，破坏产业结构健康发展，加大总量经济波动 风险, 妨碍经济增长方式转变, 降低经济增长质量效益。产能过剩问题已经引起各方的高度 关注，并且政府有关部门已经采取了一系列的措施来调整该问题，但是到目前为止仍未得到 有效的解决。在这样的背景下, 研究产能过剩的形成机制, 应该具有非常重要的指导意义。 本文基于多元统计方法, 对我国 31 个省份产能利用状况进行主成分分析, 得出产能利用率最 先体现在投入产出方面, 其次是资金利用方面, 并且产能利用状况存在明显区域差异, 经济 发达的省份产能利用状况较好，且总体东部产能利用状况较中西部好。

\section{一、引言及问题的提出}

\section{(一) 研究背景}

近些年来，中国经济由改革之初的短缺经济演变成当前的局部过剩，进入新的阶段，产 
能过剩成为一个普遍存在和经常发生的经济现象。在计划经济时代, “短缺” 是中国产品供求 的常态。我国第二次经济普查显示目前中国有近 500 种产品的生产能力利用率在 60\%以下, 尤其在工业领域中设备闲置率更是高达 40-50\%。2015 年中央工作经济会议把 “去产能” 作为 2016 年五大工作任务的首要, 由此可见解决产能过剩的意义重大。随着社会主义市场经济体 制的建立, 20 世纪 90 年代开始, 中国逐步由卖方市场转为买方市场, 告别了短缺经济时代, 随之而来，中国又出现了 “产能过剩” 现象。生产能力大于需求是市场经济条件下的正常现 象, 是经济周期性波动中市场供求关系的特殊表现，但是当生产能力超过有效需求达到一定 程度时，便会形成产能过剩，从而给经济运行带来危害。

\section{(二) 问题的提出}

进入 21 世纪以来，中国各省份经济发展呈现出不平衡发展局面。首先，表现在地方政府 干预投资和经济增长的能力过强，地方间形成恶性投资竞争，使产能扩张难以抑制。如果经 济增长过度依赖于政府直接推动的方式不能根本扭转, 那么, 投资过度问题便难以避免。其 次, 体现在许多产业的技术水平低、企业自主创新能力薄弱。这使得企业的竞争主要体现在 资源投入和产出的数量扩张, 以及价格的竞争上, 而不是集中在自主创新能力提高和质量的 改善上。其三, 产业集中度不高, 特别是许多行业由于体制方面的原因, 在长期的市场竞争 中仍无法实现资本和品牌的有效集中，如由于地方保护主义的存在及体制改革的滞后使得许 多跨部门、跨行业、跨所有制的兼并重组难以实现，其结果往往是产业竞争过度。即一些技 术和资本密集型产业难以形成垄断竞争的市场结构，结果必然是行业投资增长过度问题难以 得到市场机制的自我校正。

\section{二、产能过剩的内涵}

现实生活中，我们判断和评价一种产品过剩，是从其供给与需求之间的关系而言的。经 济学的角度认为, 当需求大于供给, 就出现供不应求, 当供给大于需求, 即出现产品过剩。 市场经济条件下，产能过剩是一种常态。因为现实经济中任何经济主体或部门都不具有关于 市场供需的完备信息, 只能在不完备信息的情形下做出决策，市场不可避免会出现供不应求 与产能过剩的情形。如今, 针对产能过剩问题, 始终存在着争论。一种观点认为, 从长期来 看, 我国仍属于发展中国家, 相对于日益增长的需求而言, 多数工业品仍处于短缺状态, 不 存在真正意义的 “产能过剩” (高路易 (2006)、张永生 (2008))。另一种观点认为, 产能过剩 是市场经济的正常现象, 完全可以通过市场机制自动调节和化解, 政府不必要过多关注和干 预（付保宗 (2011) 、李洪涛（2006)、周业樑, 盛文君 (2007))。笔者认为, 前一观点忽视了远期 需求与即期需求、潜在需求与现实需求的差异; 而后一观点忽视了我国体制机制和发展阶段 等方面的特殊国情。正确对待我国工业领域的产能过剩问题, 既要结合市场经济的一般规律, 又要考察我国的特殊体制和发展阶段特征。

总体来说，产能不能简单地把设备数量相加，就称其为产能，从全世界情况看，由于市 场的变化, 对产品结构进行调整时产能发挥 85\%左右就是正常状态, 就不能称之为产能过剩。 另外, 产能过剩是一个相对的概念。产能是否过剩, 不能只看生产能力和可能的总供给量, 更重要的是看有多少需求。因此, 认定产能过剩, 需要在纵向对比产量增长过快、过猛的同 时，还应同时指出在什么范围内、在多长的时间区间、相对于多大的有效需求而言。其次， 产能过剩是一个结构性概念。同样的产能, 质量不同、档次不同, 对经济增长的影响以及对 环境的污染程度相差迥异。

\section{三、产能过剩评价指标体系的构建}

\section{(一) 指标的选取}

通常来说，一个产业就是一个自然、经济、社会的复杂综合系统，具有很强的综合性和 复杂性。本文主要研究工业产能过剩即工业生产能力过剩, 是指实际生产能力小于最佳生产 能力而形成的过剩。是指生产部门的生产资源配置和技术运用效率低下的资产闲置状态。即 
在技术上已经具备产出条件的生产能力因市场无需求或需求不足而被长期闲置的现象。生产 能力过剩一般表现在生产能力与实际产量之间存在较大的差额, 这意味着相当部分生产能力 实际并未得到充分利用。因此, 为了正确判定各个相关指标的功能和作用, 按其重要性对相 关指标划分层级, 将指标体系分为总体层、系统层和变量层三个层级, 来突出不同层次的指 标对产能过剩的贡献性和影响程度。

总体层。用来综合反映产能过剩的总体度量, 通过对所有要素进行标准化和加权组合, 得到产能过剩综合指数, 用来反映行业产能过剩的整体情况; 系统层。将行业分解为内部具 有逻辑关系的几个子系统，从不同侧面进而体现产能过剩；基本变量层。属于评价指标体系 的基础层。行业生产能力是一个宏观意义的概念，固定资本与投资是行业产能形成的物质基 础, 行业效益、产需以及劳动就业状况在一定程度上反映了产能利用状况。因此, 本文选取 以下十个指标对我国 31 个省份的产能利用状况进行统计分析。如表 1:

表 1 工业产能过剩评价指标体系

\begin{tabular}{|c|c|c|}
\hline 总体层 & 系统层 & 基本变量层 \\
\hline \multirow{10}{*}{ 产能利用状况综合指数 } & \multirow{2}{*}{ 固定资本 } & 企业单位数（X1） \\
\hline & & 固定资产（X2） \\
\hline & \multirow{4}{*}{ 行业效益 } & 工业总产值（X3） \\
\hline & & 销售利润率（X4） \\
\hline & & 资金利润率（X5） \\
\hline & & 产值利润率（X6） \\
\hline & \multirow{2}{*}{ 产需 } & 产能利用率 (X7) \\
\hline & & 产销比 (X8) \\
\hline & \multirow{2}{*}{ 劳动 } & 从业人员平均数 (X9) \\
\hline & & 劳动生产率（X10） \\
\hline
\end{tabular}

\section{（二）数据的处理}

评价体系指标数据主要来源于《2011年中国工业统计年鉴》（见附录），其中销售利润 率=利润总额 / 营业收入 $\times 100 \%$ ，是衡量企业销售收入的收益水平的指标; 资金利润率=利 润总额/资金平均占用额 $\times 100 \%$ ，表明单位资金获得的销售利润，反映企业资金的利用效 果; 产值利润率=利润总额/销售总产值 $\times 100 \%$ 。这种衡量盈利水平的指标能从一定程度上反 映产能利用状况。

从产需的角度来看, 值得特别说明, 由于目前没有出现权威的产能利用率的测度, 因此 本文选取的产能利用率的数据是根据王否（2012） ${ }^{[5]}$ 测度得来; 产销比=工业销售总产值/工 业总产值 $\times 100 \%$, 它反映工业产品生产实现销售的程度, 即生产与销售衔接程度, 这一比率 越高, 说明产品符合社会现实需要的程度越大, 反之则小。从劳动的角度来看, 根据柯布道格拉斯生产函数, 从资本投入量与劳动投入量要素投入进行分析, 当经济处于萧条时, 生 产者就会选择减少市场要素的储备, 以减少损失。这是因为经济增长时, 生产者对要素的投 资需求就会增加, 如果过度投资, 就会造成产能过剩的情况; 而经济衰退时, 生产者对要素 的投资需求就会减少, 从而使产能过剩程度降低。所以选取从业人员平均数与劳动生产率从 一定程度上也反映了产品的利用状。

\section{四、统计分析研究结论}

\section{（一）综合评价的主成分分析法}

综合评价用数学的眼光来看, 就是建立一种从高维空间到低维空间的映射, 这种映射能 保持样本在高维空间的某种 “结构” ，其中最明显的是与 “序” 有关的结构，因为综合评价 的目的往往与排序是分不开的。在多元统计分析中, 所谓主成分分析, 是研究如何通过原变 量的少数几个线性组合来解释随机向量的方差一协方差结构。通俗地讲, 主成分分析是要在 力保数据信息丢失最少的原则下, 对高维空间进行降维处理。由上述可知, 利用多元统计分 
析的主成分分析法来解决综合评价问题是完全可行的。本章就利用主成分分析的思想对我国 各省份产能利用状况进行综合评价。

\section{（二）我国各省份产能利用状况综合评价}

首先对所选取的十个指标进行了数据标准化处理, 通过降维的思想进行了主成份分析, 此时得到的未旋转的公共因子的实际意义不好解释, 因此, 对公共因子进行方差最大化正交 旋转, 得到旋转的元件矩阵。对于第一主成分, 企业单位数 (X1) 、固定资产 (X2)、工业总 产值 (X3) 、从业人员平均数 (X9) 的系数相当, 这几个指标可以解释为第一主成分反应工 业生产中投入的资金、劳动力所产生的效果，它是 “投入”与 “产出”之比。结合表 4.2 ，第 一主成分所占信息总量为 $53.3 \%$, 在我国目前的工业企业中，经济效益首先反映在投入与产出 之比上。第二主成分除销售利润率（X4）、产值利润率（X6）、劳动生产率（X10）外，其他 指标变量的系数均相当, 所以第二主成分可以看成是企业单位数（X1）、固定资产（X2）、工 业总产值（X3）、资金利润率（X5）、产能利用率（X7）、产销比（X8）、从业人员平均数 (X9) 的综合变量, 可以解释为第二主成分反映了资金利用状况。

对SPSS的因子载荷矩阵的第 $\mathrm{i}$ 列的每个元素分别除以第 $\mathrm{i}$ 个特征根的平方根，得出主成分 分析的第 $\mathrm{i}$ 个主成分的系数如表 3 :

表 2 主成分系数表

\begin{tabular}{|c|c|c|c|c|}
\hline 指标 & 主成分 1 & 主成分 2 & 主成分 3 & 主成分 4 \\
\hline $\mathrm{x} 1$ & 0.403713 & -0.08932 & 0.190848 & -0.04746 \\
\hline $\mathrm{x} 2$ & 0.404267 & 0.052387 & 0.210613 & -0.13396 \\
\hline $\mathrm{x} 3$ & 0.414327 & 0.005757 & 0.219729 & -0.06623 \\
\hline $\mathrm{x} 4$ & -0.24847 & -0.29 & 0.583621 & 0.227556 \\
\hline $\mathrm{x} 5$ & 0.136273 & 0.625189 & 0.061352 & -0.39063 \\
\hline $\mathrm{x} 6$ & -0.23895 & 0.216831 & 0.674721 & 0.089962 \\
\hline $\mathrm{x} 7$ & 0.327571 & 0.003335 & -0.04463 & 0.532301 \\
\hline $\mathrm{x} 8$ & 0.183084 & 0.394308 & -0.09065 & 0.676085 \\
\hline $\mathrm{x} 9$ & 0.403455 & -0.0734 & 0.234972 & -0.14769 \\
\hline $\mathrm{x} 10$ & -0.24682 & 0.553523 & 0.076752 & 0.026489 \\
\hline
\end{tabular}

将标准化后的原始数据带入主成分表达式计算各省份的主成分得分,由此得出每个主成 分得分, 并且再将每个主成分的方差贡献率作为权数构造一个综合评价函数: $F=\alpha 1 \mathrm{y} 1+$ $\alpha 2 \mathrm{y} 2+\alpha 3 \mathrm{y} 3+\alpha 4 \mathrm{y} 4$, 计算出的F值大小进行排序。

将各省份在四个因子上的得分进行加权综合，得到综合得分。根据综合得分就可以看到 各省份产能利用状况。综合得分前六名的省份依次是江苏 (3.389)、广东(3.044)、山东 (2.986)、 浙江（1.885）、河南（0.928）、上海 (0.797); 综合得分最低的省份依次是西藏 (-1.957)、贵 州 (-1.692)、甘肃 (-1.59)、宁夏 (-1.479)、广西 (-1.235)。再结合个因子得分进行分析, 第 一主成分排序前六的省份依次是江苏 (5.691)、广东 (5.484)、山东 (4.644)、浙江 (3.622)、 辽宁 (1.301)、上海 $(1.214)$ 。后五名依次是西藏 $(-3.866)$ 、新疆 $(-2.717)$ 、青海 $(-2.485)$ 、 海南 $(-1.993)$ 、宁夏 $(-1.91)$ 。

\section{（三）各经济地带产能利用状况}

根据国家统计局经济地带划分，东部、中部、西部和东北地区的具体划分为: 东部 10 省

（市）包括北京、天津、河北、上海、江苏、浙江、福建、山东、广东和海南; 中部 6 省包 括山西、安徽、江西、河南、湖北和湖南; 西部 12 省（区、市）包括内蒙古、广西、重庆、 四川、贵州、云南、西藏、陕西、甘肃、青海、宁夏和新疆; 东北 3 省包括辽宁、吉林和黑 
龙江。将其综合得分进行统计分析, 东部、中部、西部以及东北三省产能利用状况对比图 1 。

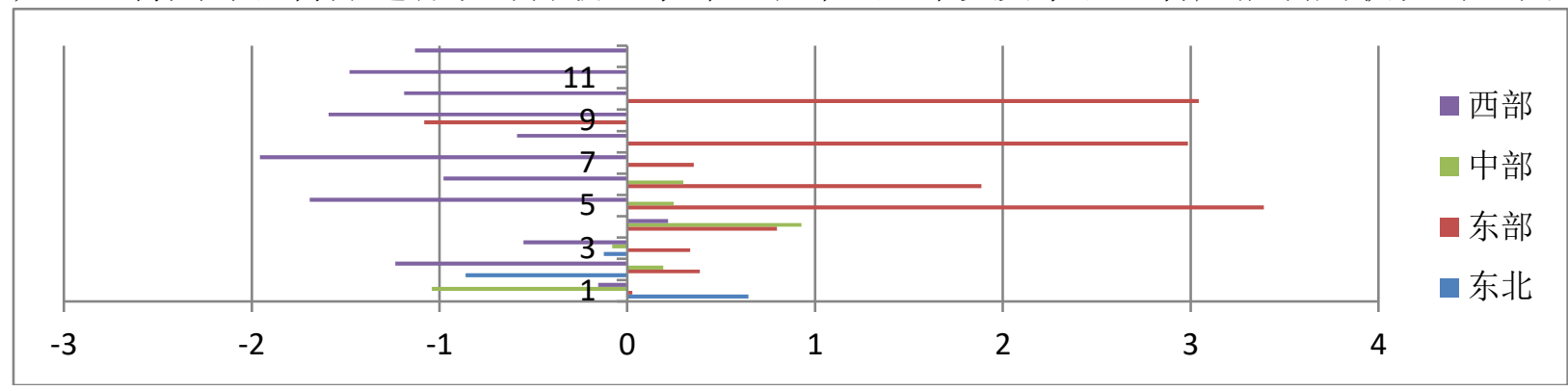

图1 东、中、西以及东北三省产能利用综合得分

由上图可知, 东部地区的产能过剩程度明显低于中、西部地区的产能过剩程度。正是由 于东部地区经济发展状况好、交通方便、生产协作条件好、技术较先进、管理水平高等优越 条件, 使得这些地区比较接近生产前沿面, 产能利用率较高。中、西部地区的产能过剩就比 较严重些, 由于这些地区所处的地理位置和经济环境所决定的, 生产技术比较落后, 产能利 用率比较低，导致了产能相对过剩比较严重。

本章小结：对我国 31 省份进行多元统计分析的综合评价实证结果表明，产能利用率层次 上看主要体现在投入与产出比，其次是资金利用状况。我国各省份产能利用率出现了较为明 显的差异, 沿海发达地区（江苏、广东、山东、浙江）工业产能利用效率综合得分明显高于 经济欠发达地区 (宁夏、甘肃、贵州、西藏), 并且呈现利用状况东部比西部明显较好的局面。 因此, 解决产能过剩首先要解决需求端与供给端的不平衡, 企业要加大创新力度, 提高企业 生产效率, 结合我国供给侧结构性改革有效化解过剩产能。西部地区可以通过学习东部地区 先进技术，提高生产效率，东部地区可以提高产品质量，以质取胜。

\section{References:}

[1] Bain, C. M., 1976, Labor hoarding and the business cycle, Journal of Political Economy 10 (2), pp. 104-123.

[2] Robert A. Hart and James R. Marry, 1996, Excess Labor Business Cycle: A Comparative Study of Japan, Germany, the United Kingdom and the United States. Economical, New Series, Vol. 63, pp. 325-342.

[3] Lin Yifu. "The wave phenomenon" and the formation mechanism of excess capacity [J]. Economic Research Journal, 2010, (10):4-19.

[4] Wang Xingyan. Excess capacity evaluation index system research [J]. Technology economy and management research, 2007, (4): 12-13.

[5] Wang Lei. China's industrial capacity measure and its relationship with the macroeconomic fluctuation of empirical research [D]. Chengdu. Wang Lei, 2012.

[6] Qi Hongming. Comprehensive evaluation method of multivariate statistical analysis [D]. Hunan: Qi Hongming,2001.

[7] Zong Han. Excess capacity in the development of our country's economy and its prevention and cure [J]. Journal of Mao zedong, deng xiaoping theory research, 2010, (1): 30-38. 